\title{
A REPRESENTAÇÃO DE PERSONAGENS GAYS NA COLETÂNEA DE CONTOS STUD E EM SUA TRADUÇÃO AS AVENTURAS DE UM GAROTO DE PROGRAMA
}

\section{REPRESENTATION OF GAY CHARACTERS IN A COLLECTION OF SHORT STORIES ENTITLED STUD AND IN ITS BRAZILIAN TRANSLATION $A S$ AVENTURAS DE UM GAROTO DE PROGRAMA}

\author{
ADAIL SEBASTIÃORODRIGUES JÚNIOR*
}

\begin{abstract}
RESUMO: Com base na tradição discursiva dos Estudos da Tradução, mais especificamente num modelo hallidayano aplicado a análises textuais, este artigo pretende desvelar como as personagens gays são representadas na coletânea de contos Stud, publicada em 1969 nos Estados Unidos da América, e em sua tradução As Aventuras de um Garoto de Programa, feita em 1998 no Brasil. O sistema de transitividade foi escolhido como recurso lingüístico para revelar como as personagens gays representavam suas experiências de mundo por meio de suas ações, comportamentos, sentimentos, relações e falas. A gramática sistêmicofuncional tem sido utilizada em pesquisas no campo dos Estudos da Tradução interessadas na compreensão da tradução literária sob a ótica do discurso. Com relação à literatura gay, o sistema de transitividade ainda não foi aplicado na investigação da representação de personagens gays em narrativas de primeira pessoa. Para levar a cabo esses propósitos, este estudo utiliza o software WordSmith Tools para quantificar os dados e analisá-los discursivamente. A metodologia adotada foi a seguinte: (i) o corpus foi digitalizado e corrigido; (ii) o corpus foi anotado manualmente, a fim de demonstrar que papel o narrador ou outra personagem gay exercia nas estórias - se eles estavam agindo, se comportando, sentindo, pensando, falando, dentre outros, conforme o processo (verbo) a eles vinculado; (iii) as personagens gays foram investigadas a partir do ponto de vista narrativo, com narrador participativo. As análises demonstraram uma frequiência alta de processos que representam participantes agindo sobre o mundo, bem como sentindo, pensando, dizendo e se comportando quando interagiam com o mundo e entre si.
\end{abstract}

Palavras-chave: contos gays; estudos da tradução; gramática sistêmico-funcional.

\footnotetext{
* Professor Adjunto I de Língua Inglesa da Universidade Federal de Ouro Preto, Instituto de Ciências Humana e Sociais, Departamento de Letras, Mariana, MG, Doutor em Linguística Aplicada pela Faculdade de Letras da Universidade Federal de Minas Gerais.
} 
ABSTRACT: Based upon a discursive tradition of Translation Studies, more specifically a hallidayan model for textual analysis, this paper aims at unveiling how gay characters are represented in a collection of short stories entitled Stud and firstly published in the 1960s in The United States of America, as well as in its translation entitled As Aventuras de um Garoto de Programa, which was done around thirty years later in Brazil. The transitivity system was chosen as a linguistic resource to make visible the way gay characters represented their world experiences through their actions, behaviours, feelings, relations and speeches. Systemic functional grammar has been used by a broad range of scholars in the field of Translation Studies, who are interested in understanding principally literary translation from a discursive perspective. Regarding gay literature, however, the transitivity system has not yet been applied to investigating the way gay characters are represented through first person narrative. So, this work, besides focussing on the system of transitivity of an English/Portuguese corpus of a collection of gay short stories, also uses WordSmith Tools software to quantify the data as well as analyse it discursively. The methodology adopted followed the following steps: (i) the whole corpus was scanned and corrected; (ii) after that, the corpus was manually tagged in order to show what role the narrator or any other gay character played in the stories - that is, if the gay characters were acting, behaving, feeling, thinking, speaking, and so forth, according to the process (verb) linked to each one of them; (iii) finally, the gay characters were investigated through the narrator's point of view, since the short stories are narrated from a first person standpoint, with a participating narrator. The analyses carried out strikingly show there is a higher frequency of processes that represent participants acting upon the world as well as feeling, thinking, saying and behaving when interacting with the world and with each other.

Keywords: gay short stories; translation studies; systemic functional grammar.

\section{INTRODUÇÃO' 1}

Seguindo a tradição das abordagens discursivas aplicadas à tradução, sobretudo de um modelo hallidayano para análises textuais, investigo, neste artigo, como as personagens gays são representadas na coletânea de contos intitulada Stud, escrita originalmente nos anos 1960 no contexto norte-americano, e em sua tradução As Aventuras de um Garoto de Programa (doravante, Garoto), traduzida cerca de trinta anos depois no contexto brasileiro. O sistema de transitividade foi eleito como recurso lingüístico para a análise das experiências de mundo das personagens gays por meio de suas ações, comportamentos, sentimentos, relações e falas. A Gramática Sistêmico-Funcional (doravante, GSF) tem sido usada por um grupo considerável de pesquisadores no campo dos Estudos da Tradução interessados, especialmente, na compreensão da tradução literária de um ponto de vista discursivo. No

\footnotetext{
${ }^{1}$ Este artigo apresenta alguns resultados de minha pesquisa de doutorado. Sou especialmente grato a Eliana Amarante de Mendonça Mendes (FALE/UFMG) pelas valiosas sugestões a uma primeira versão deste artigo.
} 
entanto, no que tange à literatura gay, o sistema de transitividade ainda não foi aplicado na investigação de como personagens gays são representadas em narrativas de primeira pessoa.

Neste artigo, além de analisar o sistema de transitividade de um corpus Inglês/Português de contos gays, também utilizo o software WordSmith Tools para quantificar os dados e interpretá-los discursivamente. A metodologia usada teve como principais etapas as seguintes: (i) todo o corpus foi digitalizado e corrigido; (ii) em seguida, o corpus foi anotado manualmente a fim de mostrar que papéis discursivos o narrador e as outras personagens gays assumiam nas estórias - ou seja, se as personagens estavam agindo, se comportando, sentindo, pensando, falando, dentre outros aspectos discursivos, de acordo com o processo (verbo) vinculado a cada uma delas; (iii) por fim, as personagens gays foram investigadas através do ponto de vista do narrador, admitindo-se que os contos são narrados em primeira pessoa, com narrador participativo.

No que se segue, contextualizo o corpus deste estudo e apresento o objetivo da pesquisa. Em seguida, teço alguns breves comentários sobre o sistema de transitividade da GSF, com ênfase nos processos e seus participantes específicos. Depois disso, relato os procedimentos metodológicos da pesquisa, a análise dos dados e, por fim, declino os comentários finais.

\section{CORPUS E OBJETIVO}

O corpus de análise desta pesquisa é uma coletânea de contos gays, escrita na década de 1960 por Samuel Steward, com o pseudônimo de Phil Andros, no contexto norte-americano, e sua tradução para o português brasileiro, feita por Dinah Klebe, ao final da década de 1990, constituindo-se, pois, em um estudo de caso. Segundo Smith (1993), os anos 1960 e 1970 nos Estados Unidos se caracterizaram pelo fortalecimento de movimentos de minorias, dentre eles o feminismo, o racismo e, sobretudo, os movimentos gays e lésbicos. Estes últimos encontraram resistência acirrada de ações coletivas radicais e discriminatórias principalmente na década de 1960 . Os movimentos sociais que ocorreram nesse período histórico norte-americano foram o ponto de partida para inúmeras manifestações e reivindicações de grupos minoritários por seus direitos, muitos dos quais iam de encontro às normas de conduta marginalizadoras estabelecidas pela ideologia política e social dos Estados Unidos.

A primeira edição da tradução de Stud para o português brasileiro, intitulada As Aventuras de um Garoto de Programa, pela Edições GLS, de São Paulo, é lançada em 1998, cerca de trinta anos depois da escrita do texto original, em um contexto social nacional em que os movimentos gays se fortaleciam e, conseqüentemente, criavam meios de expandir suas ideologias. Uma das formas utilizadas para essa expansão foi a crescente venda de livros e revistas nacionais cujas temáticas e chamadas, respectivamente, apresentavam, declaradamente, a vida gay como estilo e prática social a caminho da legitimação (Trevisan, 2004). 
Segundo Culler (1999), com o advento dos Estudos Culturais, literaturas consideradas canônicas abriram espaço para literaturas minoritárias ou marginalizadas, as quais passaram a ser o foco de atenção de teóricos dos Estudos Literários engajados na legitimação desses tipos de literatura como reconhecidamente importantes para a (re)afirmação dos grupos sociais que elas representavam. As narrativas que compõem as literaturas marginalizadas, afirma Culler (1999: 84), "são a principal maneira pela qual entendemos as coisas, quer ao pensar em nossas vidas como uma progressão que conduz a algum lugar, quer ao dizer a nós mesmos o que está acontecendo no mundo". Esta é a primeira justificativa de minha escolha pela coletânea de contos investigada. Em outras palavras, por meio dos contos de Stud e de sua tradução, é possível perceber como as personagens gays de suas estórias são representadas, isto é, como elas agem, comportam-se, pensam, falam e se relacionam umas com as outras, caracterizando, assim, formas de vida homossexual possivelmente análogas às de seus leitores (gays).

Outro ponto que chamou minha atenção para essa coletânea de contos foi o eixo histórico e político em que ela surgiu, mais precisamente, no contexto norte-americano da década de 1960, quando várias manifestações gays e lésbicas ebuliram e estabeleceram o marco para o surgimento dos movimentos gays que perduram até hoje (Berutti, 2002; Facchini, 2005). A coletânea de contos que ora analiso foi escrita em um contexto social norte-americano conturbado, em que o autor buscou expressar a cultura gay da época, sobretudo a construção social do homossexual masculino. Seus contos tentam representar o modus vivendi dos gays e suas ações em sociedade. Essa representação pode ser percebida nas escolhas lingüísticas que o autor fez para retratar a realidade gay de sua época e, ao mesmo tempo, reafirmar uma cultura que emergia dos guetos em busca de inclusão social.

No caso da tradução, cerca de trinta anos depois, a década de 1990 no Brasil caracterizou-se, segundo Trevisan (2004), como o período de reafirmação dos gays em um momento social crítico do pós-AIDS. Nesse contexto, a sociedade brasileira reergueu-se depois da avassaladora contaminação do vírus HIV causada, principalmente, por relações sexuais "ilícitas". Esse fato histórico foi denominado "peste guei", como coloca Trevisan (2004). Percebe-se, então, que a tradução de Stud surgiu em um contexto social polêmico, fato este que me levou à seguinte questão: como foram representadas as personagens gays na coletânea de contos Stud e em sua tradução As Aventuras de um Garoto de Programa? Em virtude desse questionamento, surgiu, então, o objetivo deste artigo, qual seja, quantificar e analisar discursivamente elementos centrais (processos e participantes) nas orações do corpus investigado, a fim de perceber como as personagens gays do original e da tradução foram representadas.

\section{OSISTEMA DE TRANSITIVIDADE}

Halliday (1985, 1994; Halliday e Matthiessen, 2004) sublinha que a forma prototípica de expressão das experiências de mundo exteriores aos usuários da língua ocorre por meio 
de ações e eventos, dado que os participantes agem, realizam coisas fazendo com que elas se tornem realidade. Já a expressão interna, ou subjetiva, peculiar aos participantes, se dá por meio de uma inter-relação entre as experiências exteriores e as subjetivas, representadas por intermédio de 'estados' conscienciais. A primeira forma prototípica de representação das experiências de mundo realiza-se por meio de processos materiais; a representação da inter-relação entre mundo exterior e subjetivo realiza-se através de processos mentais.

Os processos materiais são tipicamente relacionados a 'ações', cujos participantes são: "ator" (actor), aquele que executa a ação, sendo, pois, um elemento obrigatório na oração; "meta" (goal), participante que representa a entidade para quem, ou o quê, a ação é direcionada. A meta não se configura como participante obrigatório na constituição da oração, sendo, portanto, opcional. Dois exemplos extraídos de Halliday e Matthiessen (2004: 180) demonstram essa relação: (i) The lion (ator) sprang (processo material que representa a ação circunscrita apenas ao ator da oração) e (ii) The lion (ator) caught (processo material) the tourist (meta que indica a ação direcionada ao 'turista').

Os processos mentais expressam sentimentos, pensamentos e percepções, sendo, portanto, distintos dos processos materiais. Os elementos constituintes da oração circunscritos aos processos mentais são denominados "experienciador" (senser), ou aquele(a) que sente, pensa ou percebe, e o "fenômeno" (phenomenon), ou aquilo que é sentido, pensado e percebido, como no exemplo I (experienciador) don't like (processo mental) cockroaches (fenômeno) either. As características gerais dos processos mentais são: (i) as orações comumente possuem um participante humano; (ii) os fenômenos podem ser tanto coisas quanto fatos, sendo estes últimos considerados por Halliday (1994: 115) "meta-fenômenos", ou seja, um participante construído através de "projeções", ou discurso direto (quote), indireto (report), ou indireto livre (free indirect speech); e (iii) as formas verbais não-marcadas dos processos mentais ocorrem, mormente, no presente do indicativo e as formas marcadas ocorrem geralmente a partir da construção do presente-no-presente, ou construção do gerúndio.

Um aspecto discursivo característico dos processos mentais é a possibilidade de "projeção", dividindo o complexo oracional em duas orações, a "projetante" e a "projetada", sendo que apenas a projetante é realizada pelo processo mental, ao passo que a projetada pode ser constituída por qualquer outro tipo de processo. Temos um exemplo desse tipo de construção oracional em I don't believe (oração projetante com processo mental "believe") that endorsing the Nuclear Freeze initiative is the right step for California (oração projetada com processo relacional "is"). Uma construção discursiva muito explorada na constituição do discurso são as orações projetadas configuradas em discurso indireto ou indireto livre, uma vez que, segundo Gouveia (comunicação pessoal) 2, "o discurso indireto e o indireto livre prestam-se mais à manipulação se comparados ao discurso direto”. Isto significa dizer que o discurso indireto ou indireto livre sofre a manipulação de quem o produz, admitindose que a oração projetada indiretamente ou livremente é re-interpretada por quem a projeta.

${ }^{2}$ Minha interação com o Prof. Carlos Gouveia, da Universidade de Lisboa, se deu durante o Simpósio Internacional Abordagens Sistêmicas da Linguagem, em 29 de novembro de 2004, na Faculdade de Letras da UFMG. 
Tais características são igualmente típicas dos processos verbais apresentados mais à frente.

Há, ainda, um terceiro componente dessa representação que traduz a maneira como se generalizam experiências externas e internas de participantes, relacionando fragmentos de nossa visão de mundo uns com os outros, a fim de atribuir-lhes características e, portanto, significados dentro de uma rede discursiva de relações. A esse componente do sistema de transitividade Halliday dá o nome de processo relacional, isto é, o processo por meio do qual nós classificamos e identificamos uns aos outros.

Segundo Halliday (1985, 1994; Halliday e Matthiessen, 2004), existem três tipos de processos relacionais: (i) o intensivo, que expressa uma relação lógica [portador/participante + processo relacional + atributo - e.g. Sarah $\underline{i s}$ the leader.]; (ii) o circunstancial, que expressa uma relação de circunstância, acontecimento, [circunstanciador + processo relacional + circunstância em que ocorre o fato - e.g. The fair $\underline{\text { is }}$ on Tuesday.]; e (iii) o possessivo, que expressa posse por meio de relações [possuidor/participante + processo relacional + coisa possuída - e.g. Peter has a piano.].

Todos os três tipos de processos relacionais se subdividem em duas categorias: atributivas e identificativas. As atributivas conferem 'atributos', 'qualidades', aos participantes ("portadores") do processo relacional, ao passo que as identificativas conferem 'referência', 'classificação' ("identificadores"), aos participantes ("identificados”). Duas características centrais que diferenciam a categoria atributiva da identificativa são que a ordem oracional apenas desta última pode ser revertida (e.g. Alice is the clever one/The clever one is Alice) e que a identificativa pode ser também transformada em voz passiva (e.g. Cat is spelt $c$ - $a$ - $t$ ), dentro da cadência da oração em língua inglesa, ao passo que as atributivas não são reversíveis e nem transformadas em passiva. Halliday (1985, 1994; Halliday e Matthiessen, 2004) elenca algumas características mais específicas que diferenciam os processos relacionais atributivos dos identificativos. São elas:

ATRIBUTIVOS: (i) os elementos gramaticais que circundam o processo relacional são comumente adjetivos e substantivos comuns (e.g. He is Charles Darwin [substantivo]); (ii) os verbos que realizam o processo relacional são da classe dos "de atribuição" (ascriptive class), do tipo, tornar-se, manter, assemelhar-se a, ser, estar, sentir, etc., sendo os verbos ser, estar e sentir considerados 'neutros' (e.g. He grew into a man) ${ }^{3}$; (iii) o teste de identificação desses processos se encontra nos seguintes questionamentos: o quê?, como?, parecer-se com o quê?; e (iv) não há, para os atributivos, formas passivas em língua inglesa.

IDENTIFICATIVOS: (i) os elementos gramaticais que circundam os processos relacionais identificativos são comumente substantivos comuns, ou "núcleos" (heads) de grupos nominais, precedidos de artigo definido, ou outro elemento gramatical da ordem dos determinantes ("a", "the", "some", "this", "each”), ou um pronome (e.g. The chicken

\footnotetext{
${ }^{3}$ Halliday (1994: 120) apresenta, para a língua inglesa, os seguintes processos que realizam a classe dos de atribuição.

São eles: become, turn (into), grow (into), get, go, remain, stay (as), keep, seem, appear, qualify as, turn out, end up (as), look, sound, smell, feel, taste (like), be.
} 
skin was definitely the best.); (ii) os verbos que realizam o processo relacional identificativo são da classe dos "de eqüidade" (equative class), do tipo, funcionar como, indicar, sugerir, igualar-se a, exemplificar, ser, estar, tornar-se, etc., sendo os verbos ser, estar, tornar-se e permanecer considerados 'neutros' (e.g. What's the foot represent for you? I asked, like an inquiring reporter) ${ }^{4}$; (iii) o teste de identificação desses processos se encontra nos seguintes questionamentos: qual?, quem?, qual/quem ... como?; e (iv) os processos relacionais identificativos podem ser revertidos para a forma passiva com mais naturalidade em língua inglesa (e.g. Hamlet was played by Mr. Garrick).

Partindo agora para os três tipos de processos denominados por Halliday (1985, 1994; Halliday e Matthiessen, 2004) "processos subsidiários" (subsidiary processes), temos o "processo comportamental" (behavioural process), o "processo verbal" (verbal process) e o "processo existencial" (existential process). Os processos comportamentais expressam tipicamente comportamentos psicológicos e fisiológicos do "comportante" (behaver), do tipo respirar, tossir, sorrir, sonhar, dentre outros. A maioria dos processos comportamentais tem apenas um participante, o "comportante", como, por exemplo, na oração He coughed loudly, em que "He" é o comportante, "coughed" o processo comportamental e "loudly" a circunstância de modo (exemplo extraído de Eggins, 2004: 234). Quando o processo comportamental se estende a outro(s) participante(s), temos o "fenômeno" (phenomenon), como no exemplo George sniffed the soup, em que "the soup" é o fenômeno (exemplo extraído de Eggins, 2004: 234).

Os processos existenciais representam a 'existência' ou 'acontecimento' de algo (existente), tendo como verbo principal o 'haver' ou 'existir', em língua portuguesa, e o 'there to be', em língua inglesa, além de outros verbos, como, por exemplo, exist, arise e occur. O participante principal do processo existencial é o "existente" (existent), como no exemplo Should there arise any difficulties, em que "arise" é o processo existencial e "any difficulties" o "existente" (exemplo extraído de Eggins, 2004: 238).

Por fim, os processos verbais são processos relacionados à enunciação, isto é, englobam qualquer espécie de troca simbólica de constituição de significados. No que tange aos processos verbais, seus participantes não necessariamente têm de ser participantes conscientes, mas simplesmente devem verbalizar, através de signos, alguma informação ou significado. Os principais participantes do processo verbal são o "dizente" (sayer), o "receptor" (receiver) e a "verbiagem" (verbiage), como no exemplo So I asked him a question, em que "I" é o "dizente", "him" o "receptor" e "a question" a "verbiagem". Uma característica notória dos processos verbais, conforme expresso nos processos mentais mais acima, é a possibilidade de "projeções" (projections), dentro da estrutura lógicosemântica da oração, e de construções oracionais paratáticas, independentes, ou hipotáticas, dependentes, que configuram a oração de maneira interdependente entre orações, dentro de um mesmo complexo oracional. Esse tipo de configuração pode se dar, segundo Halliday

${ }^{4}$ Halliday (1994: 123) apresenta, para a língua inglesa, os seguintes processos que realizam a classe dos de eqüidade: play, act as, function as, serve as, mean, indicate, suggest, imply, show, betoken, mark, reflect, equal, add up to, make, comprise, feature, include, represent, constitute, form, exemplify, illustrate, express, signify, realize, spell, stand for, mean, be, become, remain. 
RODRIGUES - A representação de personagens gays na coletânea de contos Stud

(1985, 1994; Halliday e Matthiessen, 2004), por meio de (i) proposições (e.g. [He told me] it was Tuesday. [oração projetada]) ou (ii) propostas (e.g. [He promised] to go home. [oração projetada]).

\section{PROCEDIMENTOSMETODOLÓGICOS}

Os processos foram anotados um a um, em arquivo .txt, com as seguintes siglas em caixa alta e entre parênteses angulados $(<>)$ :

- $<$ PROMAT $>$, para processo material;

- $\langle$ PROCOMP $>$, para processo comportamental;

- $\langle$ PROMEN $>$, para processo mental;

- $\langle$ PROVERB $>$, para processo verbal;

- $\langle$ PROREL $>$, para processo relacional; e

- $\langle$ PROEXIST $>$, para processo existencial.

O uso de parênteses angulados possibilita que o software WordSmith Tools 4.0 leia ou não as siglas dos processos, visto que o pesquisador pode selecionar o comando ignorar ou não ignorar, apagando o símbolo $\langle *\rangle$ que representa os parênteses angulados no menu "Settings" na opção "Mark-up to ignore".

A divisão dos processos seguiu a classificação de Butt et al. (2000: 51), que dividem os processos em três categorias, a saber:

- Verbos de ação, divididos em processos materiais e processos comportamentais;

- Verbos de projeção, divididos em processos mentais e processos verbais;

- Verbos de estado e existência, divididos em processos relacionais e processos existenciais, respectivamente.

Alguns exemplos dessa classificação, em negrito, extraídos do corpus analisado, por meio da ferramenta Concord, são apresentados a seguir:

VERBOS DEAÇÃO:

"but I heard <PROMEN > Claytie went $<$ PROMAT > to her, and ... and ... "Yeah, Bull," I said $\langle$ PROVERB $>$, "what's it a

I laughed $\langle$ PROCOMP $>$, too, and pretty soon I left $\langle$ PROMAT $>$ and went $\langle$ PROMAT $>$ out

um belo trato em mim e no tapete sem a menor pressa e então me vesti $<$ PROMAT $>$ e fui $<$ PROMAT $>$ embora, depois de pegar $<$ PROMAT $>$ os vinte paus.

— Isto basta - ele disse $\langle$ PROVERB $\rangle$ e sorriu $\langle$ PROCOMP $\rangle$. Seus dentes eram realmente brancos. 
VERBOS DEPROJEÇÃO:

The first day, when he heard <PROMEN $>$ that he had to eat in the mess hall with the rest of the help, he said

"Clayton has made <PROMAT> a very serious charge against you. He said $<$ PROVERB $>$ that last night after the dance, you made $<$ PROMAT $>$ homosexual advances

Sentei $<$ PROCOMP $>$ e fiquei pensando $<$ PROMEN $>$ que o resto do verão poderia ser bem interessante.

Ele dormia $<$ PROCOMP $>$ nu com meias brancas de lã, pois dizia $<$ PROVERB $>$ que seus pés congelavam com o vento frio da noite.

\section{VERBOS DEESTADOEEXISTÊNCIA:}

Pete was $<$ PROREL $>$ snuggled against my side, his nose in my armpit.

There was $<$ PROEXIST $>$ a long silence then. I began to fret $<$ PROMEN $>$ again about his not

Ele falava $\langle$ PROVERB $>$ alto, era $<$ PROREL $>$ extrovertido e barulhento. Eu era $<$ PROREL $>$ o seu superior,

Havia <PROEXIST > um tumulto em minha mente. As peças do quebra-cabeça

Após a classificação de todos os processos do corpus de estudo, selecionei os nódulos $\langle$ PROMAT $\rangle$, $\langle$ PROCOMP $\rangle$, $\langle$ PROMEN $\rangle$, $\langle$ PROVERB $>$ e $\langle$ PROREL $>$, por meio da ferramenta Concord do software WordSmith Tools 4.0, para realizar a anotação manual de todos os participantes vinculados aos processos. Cada nódulo gerou um arquivo que identifica separadamente os participantes vinculados àquele processo específico. Cabe ressaltar que apenas os participantes cujas experiências de mundo construíam realidades homossexuais foram classificados por meio de anotação manual. Além disso, os processos existenciais não foram selecionados, uma vez que todas as ocorrências de $\langle$ PROEXIST $\rangle$ no corpus de estudo não estão vinculadas diretamente às personagens dos contos, apenas servindo, conforme Halliday e Matthiessen (2004: 257) esclarecem, para "apresentar participantes centrais" nas narrativas. foram:

As siglas usadas para representar as personagens gays do corpus desta pesquisa

(i) <protagonista>, para narrador/protagonista como participante direto do processo;

(ii) 〈personagem>, para personagem como participante direto do processo; e

(iii) <protagonista + personagem >, para o narrador/protagonista, juntamente com outra personagem, como participantes diretos do processo.

\footnotetext{
${ }^{5}$ Minha tradução de: “... to introduce central participants...”.
} 
RODRIGUES - A representação de personagens gays na coletânea de contos Stud

\section{ANÁLISE DOS DADOS}

\subsection{Representação do narrador/protagonista por meio de tipos de processos}

Os resultados referentes ao narrador/protagonista podem ser vistos no GRÁFICO 1 a seguir:

GRÁFICO 1 - Pontos percentuais de processos no corpus de estudo com nódulo "Protagonista"

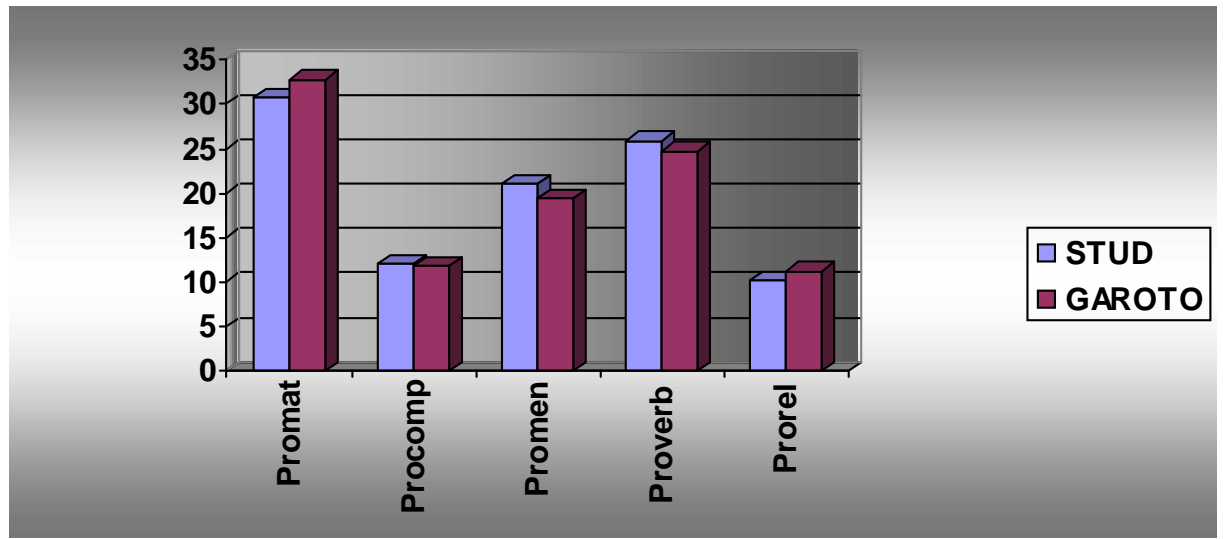

Como pode ser visto no GRÁFICO 1, o narrador/protagonista exerce o papel discursivo de ator de processos materiais em cerca de $30 \%$ em Stud, um pouco menos que em Garoto, em cuja tradução o narrador/protagonista exerce esse mesmo papel em cerca de $32 \%$ de processos materiais. Essas escolhas feitas pelo autor Phil Andros se explicam pelo fato de o narrador/protagonista construir ativamente sua realidade de mundo com as outras personagens, além de os processos materiais serem muito comuns em vários gêneros do discurso, inclusive em narrativas. Halliday e Matthiessen (2004: 174) se colocam a esse respeito:

[a] mistura de tipos de processos característicos de um texto pertencente a um registro particular tipicamente se modifica no curso do desenvolvimento de um texto. Por exemplo, o contexto ou orientação de uma narrativa é frequientemente formado por orações 'existenciais' e 'relacionais', mas a linha do evento principal é constituída predominantemente por orações 'materiais'. ${ }^{6}$ (Ênfases minhas)

Além disso, pelo fato de o narrador/protagonista ser um michê gay, por se envolver sexualmente apenas com outros gays, boa parte da construção de sua realidade de mundo

${ }^{6}$ Minha tradução de: "The mixture of process types characteristic of a text belonging to a particular register typically changes in the course of unfolding of the text. For example, the setting or orientation of a narrative is often dominated by 'existential' and 'relational' clauses, but the main event line is construed predominantly by 'material' clauses". 
se dá por meio de ações materiais com outras personagens. Segundo estudos históricos sobre a homossexualidade nos Estados Unidos (Berutti, 2002; Facchini, 2005), a escolha léxico-gramatical de processos materiais parece representar, no corpus de estudo aqui analisado, uma tentativa ativista de mostrar realidades de mundo homossexuais que emergiam nos anos 1960 no contexto social norte-americano, ainda na fase de ruptura da clandestinidade dos homossexuais nesse contexto.

A predominância de processos materiais na tradução Garoto também se explica pelo contexto de situação, dentro do eixo histórico dos anos 1990, no qual a coletânea de contos traduzida foi inserida: um contexto de reestruturação da comunidade gay do pós-AIDS, no qual seus leitores (gays) necessitavam encontrar, no discurso literário, formas de ação que viabilizassem sua naturalização após o período traumático da chamada "peste guei" (Trevisan, 2004: 438). No contexto brasileiro, a edição da tradução de Stud, lançada pela Edições GLS, representa a agenda política da própria Editora em veicular "obras de entretenimento e consciência homossexual bem positiva" (Revista Cult, 2003: 51), como salientou sua Editora-chefa, Laura Bacellar. De igual modo, As Aventuras de um Garoto de Programa, ao apresentar a constituição da realidade de mundo de um michê gay que se aventurava em experiências homossexuais com várias personagens gays, tenta retornar à cena da realidade brasileira a naturalização da boemia homossexual por meio de processos materiais presentes na tradução.

Outra explicação, de âmbito social, para a predominância de processos materiais em Garoto, como estratégia de naturalização das experiências de mundo dos gays, seria a associação da disseminação do vírus da AIDS à prática sexual entre homossexuais ao final da década de 1980 e início da de 1990. Nessas décadas, houve medidas coercitivas e de vigilância sanitária, do tipo, "fechar saunas de frequiência homossexual e proibir a realização de bailes gueis, durante o carnaval carioca" (Trevisan, 2004: 438). Com essas medidas coercitivas, as autoridades políticas da época disfarçavam a intenção camuflada de "propor um basta nos 'direitos dos homossexuais"” (Trevisan, 2004: 438).

Ademais, essas características textuais parecem ir ao encontro do estilo literário de Phil Andros. Kissack (2005), numa crítica às obras desse autor, apresenta uma síntese de sua personalidade literária:

Phil Andros foi um informante peregrino dos mistérios e fantasias multifacetadas da experiência sensual que contradizia os conceitos de infelicidade, culpa e homossexualidade trágica e cômica do mercado de massa homossexual. ${ }^{7}$

A tentativa de Andros parece ter sido a de demonstrar, por intermédio de processos materiais, o ressurgimento do homossexual à realidade social norte-americana da época. Isso parece explicar a presença proeminente desses tipos de processos no corpus sob

${ }^{7}$ Minha tradução de: "Phil Andros was a pilgrim reporting on the multi-faceted mysteries and fantasies of a sensual experience that contradicted the mass-market concepts of the unhappy, guiltridden, tragicomic homosexual." Disponível em http: //www.planetout.com/news/history/archive/ philandros.html, acesso em 2005. 
análise, visto que a ocorrência maior de processos materiais ligados ao narrador/protagonista é significativa talvez pelo fato de a obra se inserir num contexto social norte-americano que via na literatura uma forma de ação da comunidade gay da época. Em virtude disso, a proeminência de processos materiais ligados ao narrador/protagonista parece revelar uma característica social da época, isto é, uma necessidade de o leitor (gay) agir por meio da literatura.

Alguns exemplos ${ }^{8}$ de processos materiais no corpus Stud-Garoto, disponibilizados pela ferramenta Concord do software WordSmith Tools, reforçam esse posicionamento, sobretudo a tentativa de representar nos contos uma realidade gay da época de liberação de suas próprias práticas sexuais sem censuras, nem discriminações.

\section{When I finished $<$ PROMAT $>$, Pete shrugged $<$ PROMAT $>$ his shoulder just a little and moved 〈PROMAT> \\ Tirei $<$ PROMAT $>$ a minha roupa do modo como ele me disse $<$ PROVERB $>$ para fazer He was sweating $\langle$ PROCOMP $>$. He reached $\langle$ PROMAT $>$ for my belt but I unbuckled $<$ PROMAT $>$ it quickly. He grabbed $<$ PROMAT $>$ the top edge of my pants and \\ Eu o coloquei $<$ PROMAT $>$ na cadeira e me ajoelhei $\langle$ PROCOMP $>$ à sua frente para desafivelar}

Além disso, a presença significativa de processos verbais vinculados ao narrador/ protagonista do corpus Stud-Garoto, como mostrado no GRÁFICO 1, igualmente revela uma tentativa de Phil Andros de verbalizar explicitamente essas mesmas realidades homossexuais por meio dessa personagem, com o intuito de demonstrar a dinâmica dessas relações e como elas são construídas experiencialmente por intermédio dos discursos das próprias personagens. Ademais, a presença de processos verbais vinculados ao narrador/ protagonista se caracteriza também pelo gênero do discurso conto como uma narrativa em que as personagens, por meio do discurso direto ou indireto, referem-se umas às outras com o objetivo de constituírem suas próprias realidades de mundo através desses tipos de processos.

Alguns exemplos de processos verbais, extraídos do corpus Stud-Garoto, demonstram a construção discursiva das realidades de mundo do narrador/protagonista, por meio dos quais essa personagem interage com outras personagens e concomitantemente traça relações dialógicas com elas:

"I - y-yee!" I stuttered <PROVERB>. "Not on your life! That'd be too much." He went on staring at

— Isto é um verdadeiro rubor de donzela virtuosa — eu disse <PROVERB > ironicamente. Caras como você deveriam estar acostumados <PROREL>

"Take the pants off, Whitey." "Ace, not tonight," I said <PROVERB > in a halfhearted protest. I knew <PROMEN> he would pay no attention

- Tire as calças, branquelo. - Ace, esta noite não - eu disse 〈PROVERB>, num protesto sem muita veemência. Eu sabia <PROMEN> que ele não

\footnotetext{
${ }^{8}$ Os exemplos que se seguem não são os equivalentes entre original e tradução, mas apenas excertos ilustrativos das análises realizadas.
} 
A presença de processos mentais ligados ao narrador/protagonista do corpus de estudo, um pouco menos na tradução do que no original, caracteriza-o como experienciador, numa tentativa de expressar suas possibilidades de pensar sobre o mundo ao seu derredor, de querer realizar ações e percebê-las, ações estas típicas do ser humano. Halliday e Matthiessen (2004: 197), ao afirmarem que os processos mentais sinalizam uma mudança de eventos que se dão consciencialmente, ilustram os papéis de reflexão, sensação e desejo que os processos mentais representam. Essa representação expressa, pois, "ações" do narrador/protagonista no nível mental, como forma de explicitar seus desejos, receios e pensamentos e, concomitantemente, construir sua realidade de mundo subjetiva. Com efeito, as formas de representação dos pensamentos, desejos e reflexões das personagens, bem como do narrador/protagonista, se dão por meio de orações projetadas que, léxicogramaticalmente, dependem da oração projetante para realizar seu significado experiencial.

Exemplos dessas representações no corpus Stud-Garoto são vistos a seguir:

his body was black and monolithic and gleaming. And all of a sudden I felt <PROMEN> a great welling up of love or lust or desire or all of them together seu corpo era negro monolítico e radiante. E de repente senti <PROMEN> emergir em mim uma onda de amor e lascívia, ou desejo, ou todos eles juntos

And I hate <PROMEN> anybody who screws and tells-only in this case he didn't have to produzir estrelas vermelhas de encontro à cortina preta de meus olhos fechados, e eu pensei <PROMEN> que a agonia e o êxtase não fossem jamais chegar ao fim...

As presenças não muito significativas de processos comportamentais e processos relacionais vinculados ao narrador/protagonista, com levíssimas diferenças entre original e tradução, também nos levam a percebê-lo como, respectivamente, alguém que se comporta, muitas vezes junto de outras personagens, e como alguém que se relaciona e se identifica com elas. Os processos comportamentais demonstram um narrador/protagonista que constrói suas realidades de mundo em níveis fisiológicos e psicológico-comportamentais, na região limítrofe entre processos materiais, mentais e verbais. Os processos relacionais, por sua vez, servem para caracterizar e identificar o narrador/protagonista, construindo-o discursivamente como alguém que possui atributos que o identificam como uma personagem pertencente ao contexto social em que se comporta e age.

Exemplos desses tipos de processos no original e na tradução são apresentados a seguir:

I asked $\langle$ PROVERB $>$ him one day as I got up $\langle$ PROCOMP $>$ from the reclining chair in his back room and sat $\langle$ PROCOMP $>$ down on

E então, por estar tão excitado, grunhi 〈PROCOMP> avidamente, e o tomei 〈PROMAT> violenta e dolorosamente,

I had <PROREL $>$ my pants tightened and "tucked," just the way I'd had them fixed

Eu estava $\langle$ PROREL $\rangle$ nervoso e suando $\langle$ PROCOMP $\rangle$. Esta tinha sido a primeira vez que eu vira 
RODRIGUES - A representação de personagens gays na coletânea de contos Stud

\subsection{Representação das personagens por meio de tipos de processos}

Cabe, agora, investigar as outras personagens. O GRÁFICO 2 apresenta os tipos de processos ligados ao nódulo <personagem>.

GRÁFICO 2 - Pontos percentuais de processos no corpus de estudo com nódulo "Personagem"

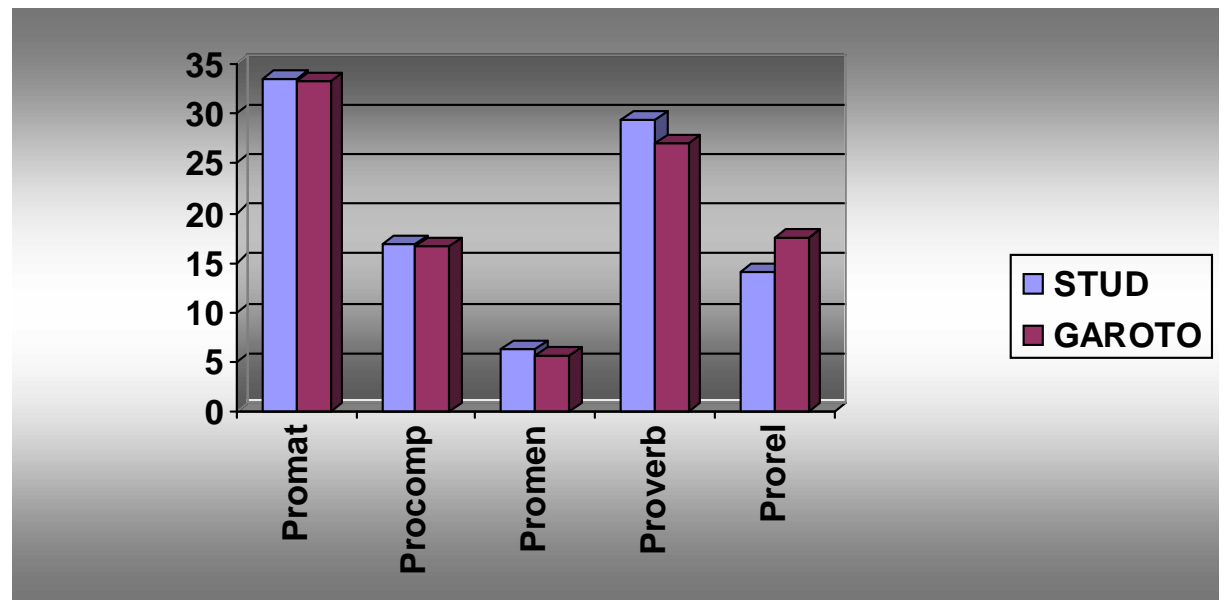

Um ponto central ligado ao GRÁFICO 2 é o fato de as personagens construírem suas realidades de mundo por meio de tipos de processos através do narrador/protagonista, uma vez que a narrativa é em primeira pessoa com narrador incorporado na trama. Percebese, então, que a figura do narrador/protagonista exerce papel fundamental na constituição das experiências de mundo, tanto suas, quanto das outras personagens, uma vez que seu ponto de vista narrativo perpassa toda a trama'.

O primeiro aspecto que chama atenção no GRÁFICO 2 é a ocorrência proeminente de processos materiais e processos verbais ligados às personagens um pouco maior do que no GRÁFICO 1 acima, tanto no original quanto na tradução. Isso se explica pelo fato de o narrador/protagonista referir-se discursivamente às personagens como forma de construir as cenas das quais elas participam e nas quais elas constroem suas realidades de mundo por meio de processos materiais e verbais. Alguns exemplos dessa característica discursiva ligada às personagens são mostrados a seguir:

Then he turned <PROMAT> his attention to the counter and started rearranging <PROMAT> things on

${ }^{9}$ Simpson (1993: 4-5) esclarece o seguinte: "In the context of narrative fiction, point of view refers generally to the psychological perspective through which a story is told". No caso do corpus aqui analisado, o ponto de vista do narrador/protagonista perpassa toda a trama, uma vez que os contos são narrados em primeira pessoa, com narrador participativo. Simpson (1993: 32) denomina esse tipo de narrativa como "homodiegetic", isto é, posicionamento participativo do narrador na estória. 
Trab.Ling.Aplic., Campinas, 46(2) - Jul./Dez. 2007

— Todos brancos? - Sim. Ele balançou <PROMAT> a cabeça. -- Melhor vir comigo - ele disse $\langle$ PROVERB $>$.

Ace growled $\langle$ PROVERB $\rangle$. "Seems like the hustlin's twice as hard up here.

— OK — ele disse 〈PROVERB $\rangle$. — Acha que pode 〈PROMAT> com ele? Ele é 〈PROREL $\rangle$ muito bem-dotado.

É importante mencionar igualmente que a ocorrência significativa de processos verbais vinculados às personagens do corpus de estudo se dá devido ao uso de discurso direto, em sua maioria, e discurso indireto, por meio dos quais as personagens, como dizentes, expressam discursivamente seus pensamentos, narram fatos e interagem entre si por intermédio do discurso que produzem. A ocorrência um pouco menor de processos verbais vinculados às personagens na tradução, em comparação com o original, justifica-se possivelmente pelas diferenças sistêmicas de cada língua, visto que na língua inglesa há um uso maior do processo verbal "said" exercendo o papel de iniciador de discurso direto ou indireto, ao passo que, na língua portuguesa, o uso de outros tipos de processos com essa função discursiva é mais freqüente do que no inglês.

Outra característica discursiva, presente no GRÁFICO 2, que chama atenção é a ocorrência menor de processos mentais quando comparada ao GRÁFICO 1. Isso se dá pelo fato de o narrador/protagonista não se referir, com freqüência significativa, aos pensamentos, desejos e reflexões das outras personagens. Tal referência ocorre, na maioria das vezes, por meio de orações projetadas, através das quais as personagens expressam seus pensamentos e concomitantemente constroem suas realidades de mundo consciencial.

Vejamos alguns exemplos no corpus Stud-Garoto:

I learned $<$ PROMEN $>$ that he liked $<$ PROMEN $>$ gin, and on the old theory that only those who have been drunk together

E ele sabia <PROMEN> como distinguir os dois perigosos e patogênicos que devem ser evitados.

I became $<$ PROREL $>$ the symbol then of all he hated <PROMEN>. "Integration", no matter how skillfully attempted or with what

Nestas horas eu me tornava $\langle$ PROREL $>$ o símbolo de tudo o que ele odiava <PROMEN>. A "integração", não importa o quão intensamente se tentasse

Já os processos comportamentais e os processos relacionais presentes no GRÁFICO 2, quando comparados aos mesmos processos do GRÁFICO 1, não apresentam diferenças significativas. Os processos relacionais do GRÁFICO 2, no entanto, ligados às personagens, ocorrem com maior freqüência na tradução em relação ao original. Talvez isso aconteça pelas possibilidades sistêmicas de tradução do processo relacional "to be" em língua portuguesa, fato que pode explicar a ocorrência significativa desses tipos de processos na tradução Garoto.

Alguns exemplos são apresentados a seguir:

He grinned $\langle$ PROCOMP $\rangle$. "Maybe I'll do just that," he said $\langle$ PROVERB $\rangle$.

He was $\langle$ PROREL $>$ naked, and his body looked horrible. It was a mottled mass of bruises 
RODRIGUES - A representação de personagens gays na coletânea de contos Stud

você é <PROREL $>$ bastante bonito. Ele me olhou <PROCOMP> de novo no rosto e riu $\langle$ PROCOMP $>$.

Você parece <PROREL> bom demais para ser desperdiçado. Ele tomou <PROMAT> um gole de cerveja

\subsection{Representação do narrador/protagonista juntamente com outras personagens por meio de tipos de processos}

Para finalizar a análise, apresento os tipos de processos do GRÁFICO 3 por meio dos quais o narrador/protagonista constrói suas realidades de mundo juntamente com outras personagens.

GRÁFICO 3 - Pontos percentuais de processos no corpus de estudo com nódulo "Protagonista + Personagem"

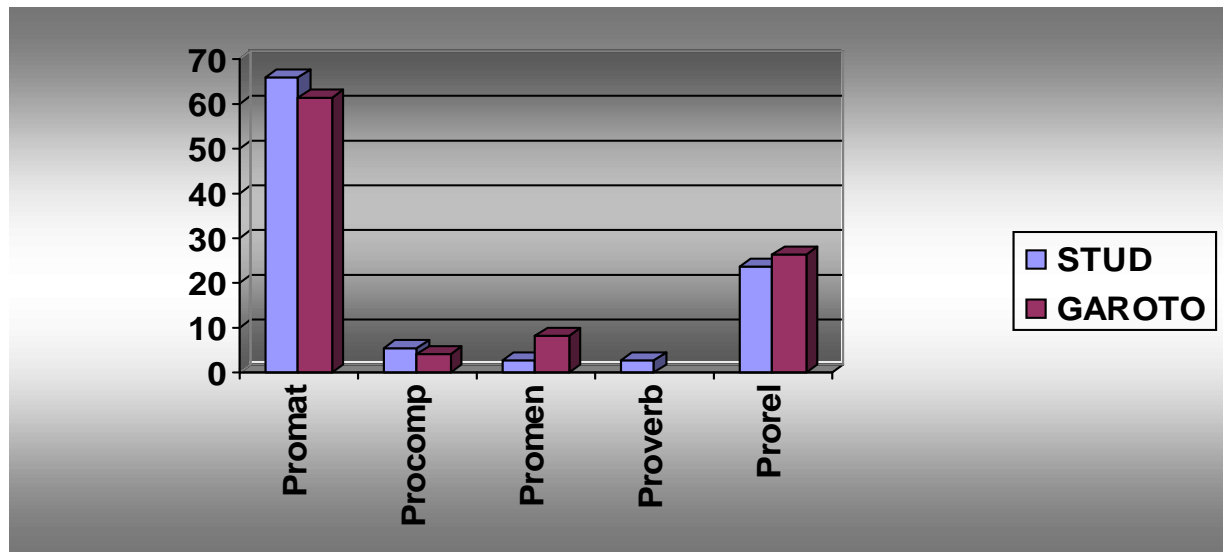

Mais uma vez, o dado que chama atenção no GRÁFICO 3 é a ocorrência significativa de processos materiais vinculados ao nódulo <protagonista + personagem>. Este dado revela que o narrador/protagonista age juntamente com outras personagens, delas dependendo para a construção das realidades de mundo que lhe são peculiares. Em contrapartida, o número menor de ocorrências de processos comportamentais, mentais e verbais, sendo que estes últimos não ocorrem na tradução Garoto, vinculados ao narrador/ protagonista em associação com outras personagens, revela que aquele constrói suas realidades de mundo como, respectivamente, comportante, experienciador e dizente muito mais como narrador/protagonista apenas, do que em conjunto com outras personagens.

Alguns exemplos dessas ocorrências são mostrados a seguir:

In the time since Ace and I had sneaked <PROMAT> out of Texas, things had not been We watched <PROCOMP> it. Some buildings came between our his little transistor radio out of his suitcase, that we found <PROMEN> out what had really happened and

After that, Ace and I managed to be <PROREL $>$ together about once a week.

Neither of us could say <PROVERB> how the alienation began, 
De vez em quando íamos <PROMAT $>$ para a minha casa,

Nós ficamos olhando $\langle$ PROCOMP $\rangle$.

e então pudemos ver <PROMEN> novamente a parada.

Ambos vestíamos <PROREL $>$ roupas idênticas, desde as jaquetas

Tal fato também pode explicar a ocorrência não muito significativa de processos relacionais ligados ao nódulo < protagonista + personagem> fornecida pelo GRÁFICO 3. Mesmo assim, os dados em que o narrador/protagonista constrói suas relações em conjunto com outras personagens, e não isoladamente, se comparados às outras construções experienciais em que o narrador/protagonista se comporta, experiencia e fala, juntamente com outras personagens, parecem ser relevantes. Esses dados, então, podem indicar uma ligação com o contexto de situação do corpus de estudo, o qual expressa uma probabilidade maior de o narrador/protagonista agir juntamente com outras personagens em suas aventuras homossexuais, bem como se identificar e se relacionar em conjunto com essas personagens, do que se comportar, experienciar e dizer coisas com elas.

\section{CONSIDERAÇÕES FINAIS}

Dentre as críticas apresentadas por teóricos da tradução, como é o caso de Lawrence Venuti (2002), à aplicação de abordagens lingüísticas em pesquisas neste campo do conhecimento, as mais freqüentemente enunciadas são as que caracterizam tais abordagens como "deliberadamente limitadas em seu poder explanatório" (p. 45), as quais "projetam um modelo conservador de tradução que restringiria indevidamente seu papel na inovação cultural e na mudança social" (p. 46). Embora a pesquisa de Venuti dialogue com outras vertentes, tais como, os Estudos Culturais e Pós-Coloniais, vejo, contrariamente às suas ponderações, que o entendimento da tradução pelo viés da Lingüística Sistêmico-Funcional (LSF) possibilita não apenas perceber as pistas discursivas que representam textualmente o fenômeno das mudanças sociais, mas, sobretudo, identificar nos textos as multifacetadas formas discursivas que promovem essas mudanças. Admitindo-se que textos são, na verdade, discursos, ou formas de representação, por meio da linguagem, das ações sociais de indivíduos de determinados contextos socioculturais (Halliday, 1978), percebo que traduções são as re-representações de discursos distintos que se imbricam e se completam. Desconsiderar, pois, as ferramentas que a Linguística Aplicada oferece para desvelar aspectos dos textos originais e de suas traduções é igualmente desconsiderar as possibilidades de identificação de questões sociais relevantes veiculadas por intermédio de textos e sua conseqüente problematização e mudança social.

A LSF tem sido usada em um número considerável de pesquisas em tradução e tem-se revelado um campo de estudos bastante profícuo para as investigações nessa linha de interesse. O que diferencia a LSF das outras abordagens discursivas dos Estudos da Tradução é precisamente a construção tripartite que a caracteriza, segundo Christie e Unsworth (2000): (i) todo e qualquer estudo da linguagem deve orientar-se conforme três funções significativas, quais sejam, representar experiências de mundo, sustentar relações 
entre interlocutores e criar discursos organizados; (ii) devido ao seu caráter sistêmico, a linguagem se modela mediante um conjunto de escolhas sistêmicas disponíveis aos usuários da língua, com significados potenciais que possibilitam a representação de suas intenções comunicativas; e (iii) a dependência do texto de seu contexto de situação e a visão do texto como unidade de análise coesa e coerente. Ao levar em conta esses três aspectos da linguagem, o(a) pesquisador(a) abre um leque de oportunidades analíticas que facilitam suas investigações e que, de igual modo, potencializam suas análises com ferramentas bem claras e previamente estabelecidas.

O potencial da LSF pôde ser visto nas análises apresentadas neste artigo. As ocorrências de processos materiais, tanto em Stud, quanto em Garoto, indicam que as personagens, inclusive o narrador/protagonista, Phil Andros, são agentes de ações. O mesmo aconteceu para os processos comportamentais, fato discursivo que revela uma característica bem marcada do corpus Stud-Garoto. As ocorrências de outros processos no corpus Stud-Garoto, quais sejam, os processos mentais, verbais e relacionais, seguiram padrões análogos em ambas as obras, fato discursivo que indica talvez uma certa equivalência entre o inglês e o português, visto que a tradução parece apresentar escolhas de tipos de processos análogas às do original. O estudo de caso realizado neste artigo abre, pois, espaço para pesquisas mais amplas cujo foco de análise seja a investigação de como personagens gays são representadas no discurso literário e que espaço elas ocupam no aeuvre da escrita gay.

\section{REFERÊNCIASBIBLIOGRÁFICAS}

BERUTTI, E. B. (2002) "Voz, Olhar e Experiência Gay: resistência à opressão". In: SANTOS, R., GARCIA, W. (orgs.). A Escrita de Adé: perspectivas teóricas dos estudos gays e lésbicos no Brasil. São Paulo: Xamã. p.23-32.

BUTT, D. et al. (2000). Using Functional Grammar: an explorer's guide. 2 ed. Sydney: Macquairie University.

CHRISTIE, F., UNSWORTH, L. (2000). "Developing socially responsible language research". In: UNSWORTH, L. (ed.). Researching language in schools and communities. London and Washington: Cassel. p.1-26.

CULLER, J. (1999). Teoria Literária: uma introdução. Trad. Sandra Guardini T. Vasconcelos. São Paulo: Beca Produções Culturais Ltda..

EGGINS, S. (2004). An Introduction to Systemic Functional Linguistics. 2 ed. London e New York: Continuum.

FACCHINI, R. (2005). Sopa de Letrinhas? Movimento homossexual e produção de identidades coletivas nos anos 90. Rio de Janeiro: Garamond.

HALLIDAY, M. A. K. (1994). An Introduction to Functional Grammar. 2 ed. London e New York: Edward Arnold. (1985). An Introduction to Functional Grammar. London e New York: Edward Arnold. 
Trab.Ling.Aplic., Campinas, 46(2) - Jul./Dez. 2007

HALLIDAY, M. A. K. e MATTHIESSEN, C. M. I. M. (2004). An Introduction to Functional Grammar. 3 ed. UK: Arnold.

HALLIDAY, M. A. K. (1978). Language as Social Semiotic. London e New York: Arnold.

REVISTA CULT. (2003). Literatura gay: bandeira política ou gênero literário. Ano IV, fev. São Paulo.

SIMPSON, P. (1993). Language, Ideology and Point of View. London e New York: Routledge.

SMITH, B. (1993). "Homophobia: why bring it up?" In: ABELOVE, H., BARALE, M. A., HALPERIN, D. M. (eds.). The Lesbian and Gay Studies Reader. London and New York: Routledge. p. 99-102.

TREVISAN, J. S. (2004). Devassos no Paraíso: a homossexualidade no Brasil, da colônia à atualidade. 6 ed. Rio de Janeiro e São Paulo: Record.

VENUTI, L. (2002). Escândalos da Tradução. Trad. Laureano Pelegrin, Lucinéia Marcelino Villela, Marileide Dias Esqueda e Valéria Biondo; revisão técnica Stella Tagnin. Bauru, SP: EDUSC.

Recebido: 15/04/2006

Aceito: 10/11/2006 